\title{
Characterization of Fusarium Yellows Resistance in Collard
}

Mark W. Farnham, Research Geneticist, USDA-ARS-U.S. Vegetable Laboratory, 2875 Savannah Hwy., Charleston, SC 29414; Anthony P. Keinath, Associate Professor, Clemson University, Dept. of Plant Pathology and Physiology, Coastal Research and Education Center, 2865 Savannah Hwy., Charleston, SC 29414; and J. Powell Smith, Senior Extension Agent, Cooperative Extension Service, Lexington, SC 29072

\begin{abstract}
Farnham, M. W., Keinath, A. P., and Smith, J. P. 2001. Characterization of Fusarium yellows resistance in collard. Plant Dis. 85:890-894.

The yellows disease of cole crops, caused by Fusarium oxysporum f. sp. conglutinans, can be very damaging to collard. Growers in the southeastern United States frequently produce collard in hot, summer months when conditions for yellows development are favorable, and thus, incidence of this disease is increasing. A collection of essentially all U.S. commercial cultivars of collard, various landraces of collard, and other representative cole crops was evaluated for response to artificial inoculation with $F$. oxysporum f. sp. conglutinans under controlledtemperature conditions. In addition, the same collection was evaluated following transplanting for response to naturally infested soil in the field during summer 1997 and 1998. In all trials, genotype had the most significant effect on percentage of diseased plants, and genotype responses ranged from resistant ( 0 to $20 \%$ diseased) to susceptible (61 to $100 \%$ diseased). There was a significant temperature effect on percentage of diseased plants in one growth chamber experiment with five genotypes that resulted primarily from an increase in disease incidence for the cultivar Blue Max at $30^{\circ} \mathrm{C}$ compared with $25^{\circ} \mathrm{C}$. Temperature was not significant in a second experiment with 20 genotypes. In the field, although significant differences were observed among genotypes and between years, a significant genotype $\times$ year interaction was not detected for percentage of diseased plants, indicating a similar ranking of genotypes for resistance between years. There was a significant correlation between results from controlled-environment studies and the field. A resistant response to $F$. oxysporum f. sp. conglutinans was expressed in certain cultivars of collard, including Flash, Heavicrop, and Morris Heading, and also in specific landraces. This resistance was stable in relatively high temperature environments used in evaluations. Results of this research indicate that choice of cultivar is a critical factor in producing collard where conditions favor infection by $F$. oxysporum f. sp. conglutinans. This information will aid in development of new yellows-resistant cultivars.
\end{abstract}

Yellows of cole crops (Brassica oleracea L.) is caused by a specific form of the persistent soilborne fungus Fusarium oxysporum Schlechtend.:Fr. f. sp. conglutinans (Wollenweb.) W.C. Snyder \& H.N. Hans. that only infects members of the Brassicaceae. Yellows is a warm-weather disease and does not develop well at temperatures below $18^{\circ} \mathrm{C}$ (11). Most cole crops, including cabbage $(B$. oleracea, Capitata Group), broccoli (B. oleracea, Italica Group), Brussels sprouts (B. oleracea, Gemmifera Group), cauliflower (B. oleracea, Botrytis Group), and collard and kale (B. oleracea, Acephala Group), have representative accessions reported susceptible to yellows (11).

Collard has been traditionally grown during cool season environments in fall,

Corresponding author: A. P. Keinath

E-mail: tknth@clemson.edu

Accepted for publication 1 May 2001.

Publication no. D-2001-0613-01R

This article is in the public domain and not copyrightable. It may be freely reprinted with customary crediting of the source. The American Phytopathological Society, 2001. ond type of yellows resistance was designated "Type A" (15). Type A resistance has been used effectively in cabbage for about 70 years and is often cited as a classic example of long-lasting, monogenic, dominant host-plant resistance (4). At present, cultivars of fresh market cabbage widely grown in the United States have Type A resistance to yellows, and outbreaks of this disease in primary cabbage production areas remain uncommon.

Type A and Type B resistances were both deemed effective against a primary form of $F$. oxysporum f. sp. conglutinans, designated as race 1 . Race 1 has been identified as the primary cause of yellows in cabbage, and it can infect all known $B$. oleracea crops $(4,11)$. Four other races of $F$. oxysporum $\mathrm{f}$. sp. conglutinans have been reported, including: race 2, primarily found on radish (2); race 3, found on common stock (Mathiola incanata) in California (2); race 4, found on common stock in New York (3); and race 5, a unique form that infects cabbage with Type A resistance (10). Although race 5 is similar to race 1 in that it attacks cabbage, it is rare and has only been found in California (10). It is generally assumed that $F$. oxysporum $\mathrm{f}$. sp. conglutinans in the southeastern United States is essentially all race 1 since cabbage that lacks Type A resistance and other susceptible $B$. oleracea crops are readily infected by yellows in this region, whereas cabbage with Type A resistance is protected against the disease.

Resistance to race 1 in cabbage may prove especially important to collard improvement. Cabbage is likely the closest relative to collard among all cole crops (5), and thus, it should be relatively easy to transfer resistance from cabbage to collard. A prerequisite for a program to develop yellows-resistant collard adapted to high temperature environments is to evaluate the relative resistance or susceptibility of existing collard germplasm and the stability of any potential resistances at high temperatures. There is little information on the relative susceptibility of cultivars of collard to yellows $(7,8)$. Thus, the specific objective of this research was to evaluate a collection of collard for seedling response to inoculation with $F$. oxysporum f. sp. conglutinans race 1 under controlledtemperature conditions in growth chambers and plant response after transplanting into soils naturally infested with race 1 during hot summer growing conditions. 


\section{MATERIALS AND METHODS}

Controlled-temperature experiments. Controlled-temperature experiments were conducted to evaluate response of collard seedlings to inoculation with $F$. oxysporum f. sp. conglutinans in two temperature regimes. Experiments were conducted in GC-15 plant growth chambers (Environmental Growth Chambers, Chagrin Falls, $\mathrm{OH})$. Inoculation and disease evaluation involved a modification of procedures described by Williams (17).

In the first experiment, four cultivars of collard, including Top Bunch (Sakata Seed America, Inc., Morgan Hill, CA), Morris Heading and Georgia (Alf Christianson Seed Co., Mt. Vernon, WA), and Blue Max (Abbott and Cobb, Feasterville, PA), and one cabbage, Bravo (Harris Moran Seed Co., Salinas, CA), were tested. Bravo cabbage contains Type A resistance to $F$. $o x$ ysporum f. sp. conglutinans and served as the resistant control in this experiment. Preliminary studies indicated that Georgia and Top Bunch were highly susceptible to $F$. oxysporum f. sp. conglutinans, while Morris Heading and Blue Max exhibited some resistance (7). Thus, in selecting these five genotypes for this first experiment, we expected them to exhibit diverse reactions when inoculated with $F$. $o x$ ysporum f. sp. conglutinans. For this and all subsequent trials in the growth chamber, seed were germinated in Metromix 360 (Grace Sierra, Milpitas, CA) in seedling trays. Trays were maintained in a walk-in growth room at $22^{\circ} \mathrm{C}$ with a 14 -h photoperiod supplying $240 \mu \mathrm{E} \cdot \mathrm{m}^{-2} \cdot \mathrm{s}^{-1}$. After 12 days, seedlings were inoculated with F. oxysporum f. sp. conglutinans.

To prepare inoculum, one isolate of $F$. oxysporum f. sp. conglutinans race 1 from broccoli (supplied by C. Kurowski, HarrisMoran Seed Co., San Juan Bautista, CA) was used in all of the controlledtemperature experiments. This isolate was grown in potato dextrose broth on a platform shaker at $150 \mathrm{rpm}$ for 4 days at $22^{\circ} \mathrm{C}$. Spores were separated from mycelium by centrifugation for $2 \mathrm{~min}$ at $4,000 \mathrm{rpm}$, and a suspension of $1.0 \times 10^{7}$ microconidia per milliliter was prepared in sterile distilled water. Twelve-day-old seedlings were removed from the potting mix, and roots were lightly washed, blotted, and immersed in the conidial suspension for 5 min. Twenty inoculated seedlings of each genotype were then planted into $26 \times 54 \times$ $6 \mathrm{~cm}$ trays filled with a 50:50 mix of Metromix 360 and washed quartz sand. Each genotype was placed at random into each of four trays. In addition, 20 noninoculated seedlings of each genotype were transferred to two trays of the same potting soil:sand mix to serve as controls. The experimental design was a split-plot with temperature treatments randomized between chambers and genotypes randomized within temperature treatments. Two trays of inoculated seedlings and one control tray were placed in each of two growth chambers. Each of the inoculated trays served as a subsample.

For 2 days, the growth chambers were set at the same conditions (constant $25^{\circ} \mathrm{C}$ with only one-third of chamber lights on for a 14-h photoperiod and relative humidity at $70 \%$ ) to allow full recovery from transplant shock. After 2 days, both chambers were set with maximum available lights $\left(600 \mu \mathrm{E} \cdot \mathrm{m}^{-2} \cdot \mathrm{s}^{-1}\right)$ with a 14 -h photoperiod, but one chamber was maintained at constant $25^{\circ} \mathrm{C}$ and the other was set to a $30^{\circ} \mathrm{C}$ day $/ 25^{\circ} \mathrm{C}$ night regime. For both temperatures, relative humidity was kept constant at $70 \%$. Throughout the experiment, a filled reservoir of water was maintained in each of the chambers, allowed to equilibrate to the temperature of each chamber, and used to water plants. Numbers of asymptomatic (healthy), symptomatic (i.e., diseased and exhibiting onesided yellowing, wilting, or necrosis of leaf tissue), and dead seedlings were recorded every 3 days, beginning 8 days after inoculation (DAI) and up to 24 DAI. The percentage of diseased plants (i.e., disease incidence) for a given genotype was calculated using the sum of symptomatic plus dead seedlings. In this and all other trials, genotypes were given a relative resistance rating based on percentage of diseased plants, with 0 to $20 \%$ designated resistant, 21 to $40 \%$ moderately resistant, 41 to $60 \%$ moderately susceptible, and 61 to $100 \%$ susceptible. This experiment was repeated, and the two trials (treated as separate replications) were combined to analyze genotype and temperature regime effects on disease incidence.

In a second experiment, 20 genotypes were tested. These included: the five genotypes evaluated in the first experiment; the collard cultivars Flash and Heavicrop (Abbott and Cobb); the collards Champion, Vates, and Green Glaze (Alf Christianson); two experimental breeding lines of collard, S.C. Header and S.C. Glaze, maintained by M. Farnham; four landraces of collard designated N.C. landrace-1, N.C. landrace2, S.C. landrace-1, and S.C. landrace-2 collected and maintained by M. Farnham; two cultivars of broccoli, Baccus and Packman (Seminis Vegetable Seed, Woodland, CA), and two cultivars of kale, Blue Knight and Blue Armor (Alf Christianson Seed Co.). This set of genotypes included all commercially available collard cultivars except one. The cultivars of broccoli and kale were included to determine their relative reaction to $F$. oxysporum f. sp. conglutinans. Bravo cabbage again served as resistant control.

Germination of seed, seedling inoculation, and setup of the second experiment were the same as that described for the first experiment, except that there was only one sample of 20 seedlings per genotype in each chamber-treatment. In addition to four trays of inoculated seedlings at each temperature, one tray of noninoculated controls (five seedlings for each of the 20 genotypes) also was included. Data were collected in the same manner in this experiment as in the first experiment. The experiment was repeated, and the two trials (treated as separate replications) were combined to analyze genotype and temperature effects on disease incidence.

Field trials in naturally infested soil. Two field trials, one each in 1997 and 1998, were conducted in a grower's field (Lakeland sand, $\mathrm{pH}$ 6.2) in Lexington County, SC, that had been abandoned for summer collard production because of a high incidence of yellows. In addition to the 20 entries tested in the second growth chamber experiment, five additional entries were included. These were: a cultivar of collard, HiCrop (Park Seed Co., Greenwood, SC); a landrace of collard designated TX landrace-1, collected and maintained by M. Farnham; and three cultivars of kale, Vates, Red Green Glaze, and Squire, obtained from E. Borchers (Hampton Roads Exp. Stn., Hampton Roads, VA). As in the controlled-temperature studies, Bravo cabbage served as the yellowsresistant control.

Seed of all genotypes were planted during the second week of May in 150-cell trays filled with Metromix 360. Prior to transplanting, the field was disked and fertilizer with 4-24-16 N-P-K was broadcast at $336 \mathrm{~kg} / \mathrm{ha}$. Seedlings were transplanted to the field on 19 June 1997 and 15 June 1998. Plants that died from transplant shock were replaced within a week of transplanting. Stand counts were taken 2 weeks following transplanting to adjust the stands for loss of plants. We assumed any plants lost within the first 2 weeks died from causes other than yellows. In both years, plants were side-dressed three times with fertilizer with 22-0-22 N-P-K at 170 $\mathrm{kg} / \mathrm{ha}$ and once with fertilizer with 33.5-0$0 \mathrm{~N}-\mathrm{P}-\mathrm{K}$ at $112 \mathrm{~kg} / \mathrm{ha}$. Insects were managed with applications of Bacillus thuringiensis at the high recommended rates. Plots were irrigated with 13 to $18 \mathrm{~mm}$ of water applied three to four times weekly as needed. Both experiments used a completely randomized design, since we had no basis for blocking the field with regard to gradients that might influence distribution of $F$. oxysporum f. sp. conglutinans. Instead, we assumed that the fungus was randomly distributed throughout the field. There were five replications of each entry with 30 plants per plot. Spacing between rows was $1.02 \mathrm{~m}$, and spacing between plants within a row was $0.3 \mathrm{~m}$.

Symptoms of yellows were evaluated visually 5,7 , and 10 weeks after transplanting by recording the number of plants without symptoms, with typical symptoms of one-sided leaf yellowing or distortion of leaves, or that were dead. The number of symptomatic plus dead plants was divided by the number of living plants recorded 2 
weeks post-transplanting to calculate percentage of diseased plants per plot. Plots were maintained several weeks after the week 10 observations, but incidence of yellows did not increase during this time. Thus, percentage of diseased plants at 10 weeks after transplanting was deemed the critical measure for evaluating relative resistance or susceptibility of all genotypes. The data sets from 1997 and 1998 were combined and analyzed together to determine genotype, year, and genotype $\times$ year effects on disease.

Statistical analysis. All analyses of variance were performed with PROC GLM of SAS (SAS Institute, Cary, NC; release 6.12). All data sets were tested for equality of variance and normality before analysis, but transformations were not necessary. Means of disease incidence for 20 genotypes tested in both the second growth chamber experiment and the field trials were compared, and Pearson correlation coefficients were calculated to determine if growth chamber and field results were correlated.

\section{RESULTS}

In the first and all subsequent controlled-temperature trials, symptoms of yellows were first observed $5 \mathrm{DAI}$ and the percentage of diseased plants among inoculated genotypes plateaued by $21 \mathrm{DAI}$ (Fig. 1). Therefore, readings at $21 \mathrm{DAI}$ were treated as peak disease incidence. There was no evidence of any disease symptoms in noninoculated controls in the first and all subsequent growth chamber trials. In addition, percentages of diseased plants were not significantly different between the two subsamples per entry within a temperature treatment (growth chamber).

Statistical analysis of the first growth chamber experiment indicated that tem- perature, genotype, and temperature $\times$ genotype interaction effects were significant $(P \leq 0.05)$ for percentage of diseased plants at 21 DAI (Table 1). At both temperatures, the resistant control, Bravo cabbage, was relatively free of disease. Conversely, Top Bunch and Georgia collard genotypes were susceptible to $F$. oxysporum f. sp. conglutinans at both temperatures, exhibiting very high percentage of diseased plants at 21 DAI. Morris Heading was significantly more susceptible than the resistant cabbage at both temperatures, but exhibited a relatively resistant response compared with Top Bunch and Georgia. The significant temperature and genotype $x$ temperature effects for percentage of diseased plants at 21 DAI are largely explained by a nearly fourfold increase in percentage of diseased plants for Blue Max at $30^{\circ} \mathrm{C}$ than at $25^{\circ} \mathrm{C}$ (Table 1). At $25^{\circ} \mathrm{C}$, Blue Max was not significantly different from resistant Bravo, but it was moderately susceptible at $30^{\circ} \mathrm{C}$.

In the second experiment in growth chambers, analysis of variance indicated that only the genotype effect was significant, whereas temperature and genotype $\times$ temperature effects were not significant (Table 2). Bravo, Morris Heading, Blue Max, Top Bunch, and Georgia exhibited similar levels of disease to the first experiment. Among the additional genotypes of collard, Flash, Heavicrop, Champion, and N.C. landrace- 1 and -2 were similar to Bravo in disease response at both temperatures. Other genotypes of collard, including Vates, S.C. landrace-2, and Green Glaze, were moderately resistant or moderately susceptible, exhibiting consistently more disease than Bravo but less than the susceptible Top Bunch or Georgia. Both cultivars of broccoli were more susceptible than the resistant control, but Baccus had a significantly lower percentage of diseased plants than Packman. Both cultivars of kale were susceptible, exhibiting $85 \%$ or greater diseased plants.

Statistical analysis of 1997 and 1998 field trials showed highly significant differences between years and among genotypes for percentage of diseased plants 10 weeks after transplanting (Table 3 ) but no year $\times$ genotype interaction. In general, yellows was more severe in 1997 than in 1998. The resistant cabbage Bravo had 6.1 and 2.2\% diseased plants in 1997 and 1998, respectively. The most susceptible entry in both field trials was Blue Armor kale, with 76.9 and $69.8 \%$ diseased plants, respectively, in 1997 and 1998. Among genotypes of collard, Flash, Heavicrop, Morris Heading, Top Bunch, N.C. landrace-1 and -2, HiCrop, Blue Max, Champion, and S.C. landrace-2 were not significantly different from Bravo in both years. Most of these genotypes always had a

Table 1. Mean percentage of diseased plants at 21 days after inoculation with Fusarium oxysporum f. sp. conglutinans race 1 for $\mathrm{cv}$. Bravo cabbage and four collard cultivars grown in $25^{\circ} \mathrm{C}$ day $/ 25^{\circ} \mathrm{C}$ night or $30^{\circ} \mathrm{C}$ day $/ 25^{\circ} \mathrm{C}$ night regimes in a growth chamber

\begin{tabular}{lcc}
\hline & \multicolumn{2}{c}{ Diseased (\%) } \\
\cline { 2 - 3 } Cultivar & $\mathbf{2 5 / 2 5 ^ { \circ } \mathbf { C }}$ & $\mathbf{3 0 / 2 5}^{\circ} \mathbf{C}$ \\
\hline Bravo & 2.5 & 5.3 \\
Top Bunch & 95.0 & 97.4 \\
Morris Heading & 16.2 & 25.1 \\
Georgia & 80.8 & 97.9 \\
Blue Max & 12.5 & 44.1 \\
LSD $_{0.05}{ }^{\mathrm{z}}$ & 11.7 & 11.4 \\
\hline
\end{tabular}

${ }^{\mathrm{z}}$ Fisher's protected least significant difference, $P=0.05$. Each $\mathrm{LSD}_{0.05}$ was computed from separate analysis of variance by temperature.
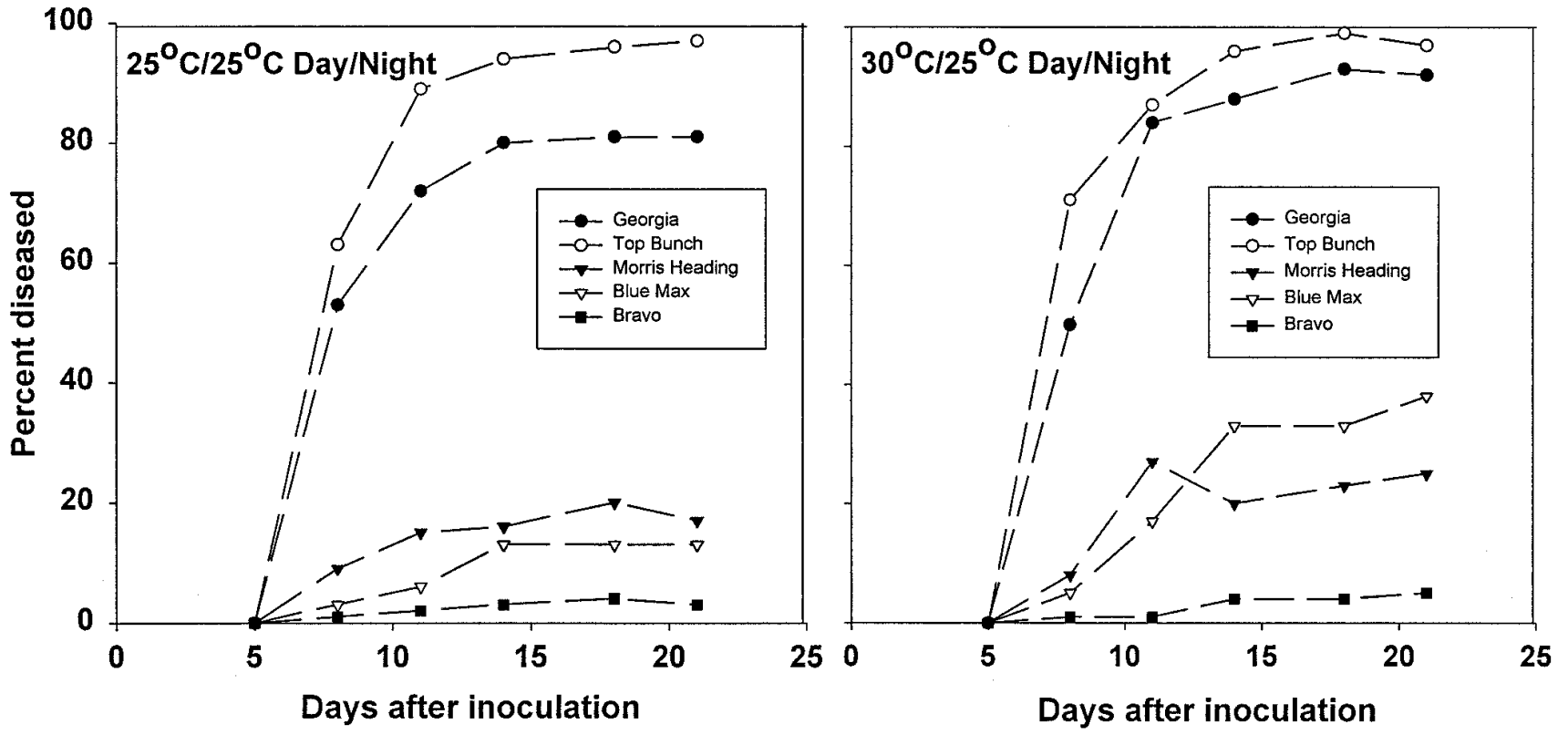

Fig. 1. Mean percent diseased or dead plants for four collard cultivars and cabbage cv. Bravo following inoculation with Fusarium oxysporum f. sp. conglutinans in growth chambers with either a constant $25^{\circ} \mathrm{C}$ temperature regime or a day/night regime of $30^{\circ} \mathrm{C} / 25^{\circ} \mathrm{C}$. 
higher mean percentage of diseased plants than Bravo, but these differences were not statistically significant $(P \leq 0.05)$. The relatively resistant response for Top Bunch in the field was very different than the susceptible response for this entry in the growth chamber seedling tests. S.C. Header and Vates were significantly more susceptible than Bravo in 1998 but not in 1997. Conversely, S.C. landrace-1 was more susceptible than the resistant control in 1997 but not in 1998. The remaining collard entries had significantly greater percentage of diseased plants than Bravo in both years. As in the growth chamber, Georgia was susceptible to yellows in the field. For broccoli, Baccus was not significantly different from the resistant control in either year, whereas Packman was significantly more diseased than the resistant control in 1997 but not in 1998. In general, cultivars of kale were susceptible to $F$. oxysporum f. sp. conglutinans and exhibited a high percentage of diseased plants (38.0 to 76.9) in both years.

Means for percentage of diseased plants for the 20 different genotypes tested in both the growth chamber and the field were significantly correlated between the two types of disease evaluation trials $(P<$ $0.001)$. Correlation coefficients between genotype means for percent diseased plants at $25^{\circ} \mathrm{C}, 30^{\circ} \mathrm{C}$, or the combined mean of 25 and $30^{\circ} \mathrm{C}$ in growth chambers and the genotype means derived by averaging results of both field trials were $0.729,0.709$, and 0.730 , respectively. When Top Bunch, which exhibited drastically different responses in seedling tests versus field tests, was removed from the analysis, the correlation coefficients increased to 0.870 , 0.856 , and 0.879 , respectively.

\section{DISCUSSION}

Symptoms of yellows were readily observed in seedling evaluations within growth chambers where 12-day-old seedlings were artificially inoculated with $F$. oxysporum $\mathrm{f}$. sp. conglutinans and in field trials where 4- to 5-week-old plants were set into naturally infested soil. Overall, percentages of diseased plants were higher in seedlings in the growth chambers than they were in the field. This may have been caused by all seedlings contacting the pathogen in the artificially inoculated trials, whereas some transplants probably escaped infection in the field, because the fungus likely was not distributed evenly or in sufficiently high inoculum densities to affect all plants uniformly. Alternatively, the relatively older plants used in the field studies may have been less susceptible compared with the seedlings inoculated in the growth chamber.

Across all trials, the resistant control Bravo exhibited the fewest diseased plants of all genotypes. Some individual plants of Bravo, known to contain type A resistance, exhibited symptoms of yellows, but this was relatively rare. Walker and Smith (16) also observed some symptoms in a few individuals of cabbage from homozygous lines expressing type A resistance, and such individuals were more frequent at temperatures above $28^{\circ} \mathrm{C}$. Interestingly, we observed no significant difference between Bravo in the $25^{\circ} \mathrm{C} / 25^{\circ} \mathrm{C}$ and $30^{\circ} \mathrm{C} / 25^{\circ} \mathrm{C}$ regimes in growth chambers, and susceptible individuals of Bravo also were infre- quent in the field trials in Lexington, where soil temperatures typically exceed $30^{\circ} \mathrm{C}$ during summer. Although there has been some conflicting discussion about whether or not type A resistance may break down at $28^{\circ} \mathrm{C}$ or higher $(4,11,16,17)$, it appeared very stable at temperatures of $30^{\circ} \mathrm{C}$ and above that occurred in our trials. It is also possible that rare susceptible individuals in Bravo could represent susceptible inbreds

Table 2. Mean percentage of diseased plants 21 days after inoculation with Fusarium oxysporum f. sp. conglutinans for 20 genotypes of Brassica oleracea grown in $25^{\circ} \mathrm{C}$ day $/ 25^{\circ} \mathrm{C}$ night or $30^{\circ} \mathrm{C}$ day $/ 25^{\circ} \mathrm{C}$ night regimes in a growth chamber

\begin{tabular}{|c|c|c|c|}
\hline \multirow[b]{2}{*}{ Crop } & \multirow[b]{2}{*}{ Genotype } & \multicolumn{2}{|c|}{ Diseased (\%) } \\
\hline & & $25 / 25^{\circ} \mathrm{C}$ & $30 / 25^{\circ} \mathrm{C}$ \\
\hline Cabbage & Bravo & 0.0 & 5.0 \\
\hline \multirow[t]{15}{*}{ Collard } & Flash & 0.0 & 15.0 \\
\hline & Heavicrop & 2.5 & 0.0 \\
\hline & Champion & 5.0 & 20.0 \\
\hline & Morris Heading & 7.5 & 15.0 \\
\hline & Blue Max & 7.5 & 35.0 \\
\hline & N.C. landrace-1 & 12.5 & 20.0 \\
\hline & S.C. landrace-1 & 12.5 & 40.0 \\
\hline & N.C. landrace-2 & 20.0 & 15.0 \\
\hline & S.C. Header & 21.5 & 35.0 \\
\hline & Vates & 30.0 & 52.5 \\
\hline & S.C. landrace-2 & 40.0 & 22.5 \\
\hline & Green Glaze & 40.0 & 50.0 \\
\hline & S.C. Glaze & 52.5 & 65.0 \\
\hline & Georgia & 72.5 & 75.0 \\
\hline & Top Bunch & 92.5 & 100.0 \\
\hline \multirow[t]{2}{*}{ Broccoli } & Baccus & 32.5 & 45.0 \\
\hline & Packman & 87.5 & 82.5 \\
\hline \multirow{3}{*}{ Kale } & Blue Knight & 85.0 & 100.0 \\
\hline & Blue Armor & 97.5 & 95.0 \\
\hline & $\mathrm{LSD}_{0.05^{\mathrm{z}}}$ & 24.4 & 27.9 \\
\hline
\end{tabular}

z Fisher's protected least significant difference, $P=0.05$. Each $\mathrm{LSD}_{0.05}$ was computed from separate analysis of variance by temperature.

Table 3. Mean percentage of diseased plants 10 weeks after transplanting 25 genotypes of Brassica oleracea to a field naturally infested with Fusarium oxysporum f. sp. conglutinans

\begin{tabular}{|c|c|c|c|}
\hline \multirow[b]{2}{*}{ Crop } & \multirow[b]{2}{*}{ Genotype } & \multicolumn{2}{|c|}{ Diseased $(\%)^{y}$} \\
\hline & & 1997 & 1998 \\
\hline Cabbage & Bravo & 6.1 & 2.2 \\
\hline \multirow[t]{17}{*}{ Collard } & Flash & 3.5 & 14.5 \\
\hline & Heavicrop & 7.3 & 3.8 \\
\hline & Morris Heading & 10.0 & 8.3 \\
\hline & Top Bunch & 14.8 & 6.2 \\
\hline & N.C. landrace-1 & 15.4 & 3.6 \\
\hline & Hi Crop & 16.0 & 3.0 \\
\hline & N.C. landrace-2 & 16.4 & 5.7 \\
\hline & S.C. Header & 19.6 & 24.6 \\
\hline & Blue Max & 20.9 & 5.7 \\
\hline & Champion & 20.9 & 7.8 \\
\hline & S.C. landrace- 2 & 24.3 & 17.3 \\
\hline & Vates & 25.9 & 18.8 \\
\hline & S.C. landrace-1 & 26.2 & 8.1 \\
\hline & Green Glaze & 29.4 & 28.1 \\
\hline & S.C. Glaze & 37.7 & 32.4 \\
\hline & Georgia & 69.9 & 55.9 \\
\hline & TX landrace-1 & 71.1 & 66.4 \\
\hline \multirow[t]{2}{*}{ Broccoli } & Baccus & 20.4 & 2.7 \\
\hline & Packman & 37.0 & 16.9 \\
\hline \multirow[t]{6}{*}{ Kale } & Blue Knight & 46.8 & 38.0 \\
\hline & Red Gleen Glaze & 69.5 & 38.8 \\
\hline & Vates & 70.5 & 48.1 \\
\hline & Squire & 74.1 & 58.5 \\
\hline & Blue Armor & 76.9 & 69.8 \\
\hline & $\mathrm{LSD}_{0.05}{ }^{\mathrm{z}}$ & 20.1 & 16.4 \\
\hline
\end{tabular}

y Mean of five replications of 30 plants each.

${ }^{\mathrm{z}}$ Fisher's protected least significant difference, $P=0.05$. 
that occur within the hybrid. Generally, the self-incompatibility system used to make cabbage hybrids is not $100 \%$ effective, allowing for a low frequency of selfing that results in the presence of inbred seed among hybrid seed.

The relatively high percentages of diseased plants for genotypes of kale in both growth chamber and field trials indicate a general susceptibility of this cole crop to yellows. The response of kale in the field confirmed that $F$. oxysporum f. sp. conglutinans was generally present and well distributed throughout the field site, which was recognized by the cooperating grower as "heavily" infested. The susceptible response of kale in these trials compared with the resistant cabbage control provides a good differential with which to judge the relative resistance or susceptibility of collard, the primary focus of our research.

This study provides the first definitive evidence that significant resistance to yellows is expressed in certain commercial cultivars of collard, e.g., Flash and Heavicrop, as well as in some relatively uncharacterized collard germplasm, e.g., N.C. landrace-1. In contrast, other cultivars of collard, e.g., Georgia, or germplasm (TX landrace-1) are susceptible. Although increasing day temperature from 25 to $30^{\circ} \mathrm{C}$ in growth chamber studies increased disease incidence for some entries, in most cases the increases were not significant and the relative rank of entries did not change at the higher temperature. A notable exception is Blue Max, which appeared relatively resistant at $25^{\circ} \mathrm{C} / 25^{\circ} \mathrm{C}$ but moderately susceptible at $30^{\circ} \mathrm{C} / 25^{\circ} \mathrm{C}$. It seems highly likely that Blue Max might contain a different resistance than type A expressed in Bravo, since the cabbage control was little impacted by temperature.

Overall, results of growth chamber seedling evaluations were correlated with field evaluations. Top Bunch was the only outlier for this trend, exhibiting 90 to $100 \%$ diseased plants in the growth chamber studies but responses not significantly different from resistant Bravo in the field. This extreme difference for Top Bunch indicates that the growth chamber and field tests assessed different attributes of infection by Fusarium and will not give the same result for all possible genotypes of collard and other B. oleracea crops. We chose to use transplants in our field studies, as transplanting is the common practice to establish collard when environmental conditions are too harsh for direct seeding.

Results of this study show that choice of cultivar is probably the most critical factor in producing collard where $F$. oxysporum $\mathrm{f}$. sp. conglutinans may be present in the soil and high temperatures may favor the disease. By growing resistant cultivars such as Flash, Heavicrop, or Morris Heading, producers will minimize the risk of yellows. Results also suggest that development of new yellows-resistant collard cultivars could be accomplished using two different strategies. One approach would involve moving the type A resistance in cabbage to a collard background. Since Farnham (5) showed that cabbage and collard are closely related, this approach should prove feasible. Another approach would be to develop a new cultivar of collard using the resistance already present in certain cultivars such as Flash. This latter alternative may have the advantage of exploiting possible new genes for resistance not already used in cabbage.

New cultivars of cabbage in the United States are all screened for resistance to yellows. Most determinations of resistance are based on some form of seedling test similar to the one we conducted in a controlled-temperature environment. Since results of our growth chamber and field evaluations were highly correlated, we suggest that programs aimed at developing new collard cultivars with yellows resistance should also utilize a seedling test such as the one we described. Using this approach, a differential response to $F$. $o x$ ysporum f. sp. conglutinans should be readily observed, and individuals of collard determined to be resistant could be advanced and used as parents in breeding for resistance to yellows or ultimately used as resistant, commercial cultivars.

\section{ACKNOWLEDGMENTS}

We thank J. S. P. Nannes, E. Gomperts, V. Dubose, and W. May III for technical assistance and Walter P. Rawl and Sons for use of the field naturally infested with F. oxysporum f. sp. conglutinans.
LITERATURE CITED

1. Anderson, M. E. 1933. Fusarium resistance in Wisconsin Hollander cabbage. J. Agric. Res. 47:639-661.

2. Armstrong, G. M., and Armstrong, J. K. 1952. Physiologic races of the Fusaria causing wilts of the Cruciferae. Phytopathology 42:255257.

3. Armstrong, G. M., and Armstrong, J. K. 1965. Races of Fusarium oxysporum f. sp. conglutinans; race 4, new race; and a new host for race 1, Lychnis chalcedonica. Phytopathology 55:525-530.

4. Dixon, G. R. 1981. Vegetable Crop Diseases. MacMillan Publishers LTD, London.

5. Farnham, M. W. 1996. Genetic variation among and within United States collard cultivars and landraces as determined by randomly amplified polymorphic DNA markers. J. Am. Soc. Hortic. Sci. 121:374-379.

6. Jones, L. R., and Gilman, J. C. 1915. The control of cabbage yellows through disease resistance. Wis. Agric. Exp. Stn. Res. Bull. 38.

7. Keinath, A. P., and Farnham, M. W. 1993. Evaluation of resistance to Fusarium yellows in collard and kale at high temperatures. Biol. Cult. Tests 8:19.

8. Keinath A. P., Farnham, M. W., Smith, J. P., and Nannes, J. S. P. 1998. Reaction of 26 cultivars of Brassica oleracea to yellows in naturally infested soil. Biol. Cult. Tests 13:155.

9. Kucharek, T., Jones, J. P., Hopkins, D., and Strandberg, J. 1992. Some diseases of vegetable and agronomic crops caused by Fusarium in Florida. University of Florida, Gainesville, Coop. Ext. Serv., Circ. 1025.

10. Ramirez-Villupadua, J., Endo, R. M., Bosland, P., and Williams, P. H. 1985. A new race of Fusarium oxysporum f. sp. conglutinans that attacks cabbage with type A resistance. Plant Dis. 69:612-613.

11. Sherf, A. F., and MacNab, A. A. 1986. Vegetable Diseases and Their Control. John Wiley \& Sons, New York.

12. Tisdale, W. B. 1924. Influence of soil temperature and soil moisture upon the Fusarium disease in cabbage seedlings. J. Agric. Res. 24:55-86.

13. Walker, J. C. 1930. Inheritance of Fusarium resistance in cabbage. J. Agric. Res. 40:721745.

14. Walker, J. C., and Blank, L. M. 1934. Fusarium resistant Danish Ballhead cabbage. J. Agric. Res. 49:983-989.

15. Walker, J. C., and Hooker, W. J. 1945. Plant nutrition in relation to disease development. I. Cabbage yellows. Am. J. Bot. 32:314-320.

16. Walker, J. C., and Smith, R. 1930. Effect of environmental factors upon the resistance of cabbage to yellows. J. Agric. Res. 41:1-15.

17. Williams, P. H. 1985. Crucifer Genetics Cooperative Resource Book. University of Wisconsin, Madison. 